\title{
A Conceptual Framework for the Association between Relationship Conflicts and Employees' Intention to Leave
}

\author{
Ranitha Sachinthana Weerarathna ${ }^{1}$, Sharmini Perera ${ }^{2}$ \\ ${ }^{1}$ Lecturer, Department of Business Management, Faculty of Business, Sri Lanka Institute of Information \\ Technology, Malabe, Sri Lanka \\ ${ }^{2}$ Former Senior Lecturer, Department of Business Management, Faculty of Business, Sri Lanka Institute of \\ Information Technology, Malabe, Sri Lanka \\ Correspondence: Ranitha Sachinthana Weerarathna, Lecturer, Department of Business Management, Faculty of \\ Business, Sri Lanka Institute of Information Technology, Malabe, Sri Lanka. Email: ranitha.w@ sliit.lk
}

Received: August 9, 2018

doi:10.5539/ibr.v11n10p86
Accepted: September 10, $2018 \quad$ Online Published: September 20, 2018

URL: https://doi.org/10.5539/ibr.v11n10p86

\begin{abstract}
The main objective of this research paper to conceptualize a model to test the association between relationship conflicts and employees' intention to leave with the support of past theories and research findings. This research paper contains the definitions for variables related to relationship conflicts and employees' intention to leave from the organization and also it explains models which explain the interconnections among two variables. The conceptualization of this research includes a logically developed model that leads to identify the relationships between the independent variable and dependent variable. The proposed model suggested that there is an association between relationship conflicts and employees' intention to leave.
\end{abstract}

Keywords: relationship conflicts, employees' intention to leave and organizational conflicts

\section{Introduction}

Human resources who are working in different organizations consist with different personalities, different values and beliefs, different expectations and different abilities and it is difficult to manage them. Thus, it is clearly established that the human factor is significant to every organizations, whether it is profit making, nonprofit, government, private or semi government organization. Furthermore, the primary objective of any business owners is profitability with optimum utilization of resources. Organizations or business success depends on employee retention. Employee retention helps to minimize the wastage of human resources. Long term success of the organization depends on the retention of talented and competent employees in the organizations. Employee retention is influenced to the customer satisfaction, customer retention, organizational performance etc.

As described above employees who are working in different organizations consist with different personalities, different values and beliefs, different expectations and different abilities and it is difficult to manage them. Due to different type of personalities, employees may have personality clashes, attitudes problems and relationship conflicts with their superiors, colleagues and with the management. Due to these relationship conflicts employees may act or react in an unexpected way. They may sabotage the business plans. Further, it well leads to employee turnover as well. In fact, management of employees is more difficult than management of any other resources.

For any contemporary organizations to perform effectively, interdependent individuals and groups must establish working relationship across organizational boundaries, between individuals and among groups. Individuals or group in organizations may depend on one another for information, assistance or coordinated action. But the fact is that they are interdependent. Such interdependence may foster either cooperation or conflict.

\section{Organizational Conflicts}

As per the objectives of this study, it is intended to build conceptual framework to prove the association between relationship conflicts and employees' intention to leave from the organization, it is essential to review the definitions of organizational conflicts. 
Organizational conflict refers as any interaction between workers and clusters with irreconcilable differences or incompatible characters (Rahim, 2001). Kumar (2009) defined organizational conflicts as a behavior demonstrated by organizational members which is expended in opposition to other members.

\subsection{Intra-group Conflict}

Past researchers found that there are two types of intra group conflicts: relationship conflicts and task conflicts (Jehn 1994; Amason, 1996; \& Jehn; 1997). Later, researchers added third type of intra-group conflict and labeled it as process conflict. This research study highly focuses on relationship conflicts which come under intra-group conflicts.

\subsubsection{Relationship Conflicts}

Researcher's current interest among intra-group conflicts is relationship conflicts. Relationship conflicts are also known as affective conflict or emotional conflict in the literature (Pelled et al., 1996). Relationship conflict can be defined as perception among group members of interpersonal incompatibility and includes annoyance and animosity (Medina et al., 2005). Relationship conflict can be defined as an awareness of interpersonal incompatibilities includes affective components such as feeling tension and frictions and it deals with personnel issues such as dislike among group members and feelings such as annoyance, frustration and irritation (Jehn and Mannix, 2001). According to Jehn (1995) relationship conflicts exists when there are interpersonal incompatibilities among group members which they feel tension, animosity and annoyance among members within the same group. Relationship conflict can be referred as disagreements among group members about interpersonal issues, such as personality differences or differences in norms and values (De Wit et al., 2012).

There are number of studies which focused about influence of relationship conflicts on different affective reactions including frustration, anger and annoyance and withdrawal behaviors by using qualitative and quantitate methods. Further, relationship conflict is negatively associated with affective reactions. Relationship conflicts have positive influence on the desire to leave the current job. Relationship conflict decrease employee's satisfaction and psychological well-being of the employees (Medina et al., 2005).

There are differences between task conflicts and relationship conflicts. Firstly, relationship conflicts occurred due to incompatibilities in feelings and emotions. On other hand, task conflicts aroused due to incompatibilities in job duties and responsibilities of the conflicting parties (Riaz and Junaid, 2013). Jehn (1997) presented an alternative approach to differentiate between task and relationship conflicts, relationship conflicts generally decrease satisfaction and interferes with task performance. But task conflict can be advantageous to task performance when working on non-routine task.

Researcher has conducted comprehensive analysis about definitions of relationship conflicts and the measurement used by previous researchers. Jehn (1995) defined relationship conflicts as it can be seen when there are interpersonal incompatibilities among group members which inclusive animosity, tension and annoyance. Jehn (1995) used extent of friction, personality conflicts, tension, emotional conflicts, liking and satisfaction with group to measure the relationship conflicts. Relationship conflicts refer disagreement which based on personal and social issues (Jehn, Northcraft and Neale, 1999; Jehn and Chatman, 2000). Those authors used extent of friction, personality conflicts, tension and emotional conflicts. Jehn and Manix used three items to measure relationship conflicts including; extent of relationship tension, how often people get angry, extent of emotional conflict.

\section{Employees' Intention to Leave}

The study of employee intention to leave is an important area in both practical and theoretical of Organizational Behaviour and Human Resource Management. Employee intention to leave refers to conscious and deliberate willfulness to leave the organization and it is considered as last part of a sequence in the withdrawal cognition process (Basak et al., 2013). Prior researches and studies provide strong support that intention leave or quit is strongest predictor of actual employee turnover. Steel and Ovalle (1984) stated that employees' intention to leave is more valid predictor for actual employee turnover than overall job satisfaction.

There are various factors which affect to employees' intention to leave. Based on literature, there are three reasons can be identified that affect for employees' intention to leave. Current study selected three reasons as job hopping and perceived alternative employment opportunities of employees' intention to leave from organization.

\section{Theoretical Model Introduced for Relationship Conflicts and Turnover Intentions (Hill et al., 2015)}

This model developed by Hill et al. (2015) identified that, changes in role ambiguity over time, reflects the indirect effect of increases in role ambiguity on increases in turnover intentions through increases in relationship 
conflicts. This model proved that increases in role ambiguity are positively related to increases in relationship conflict over time and also increases in relationship conflicts are positively related to increase in turnover intentions over time. Further same researchers argued that increases in role ambiguity may lead to relationship conflict development through of negative emotions with involving in ego-defensive behaviors and self-serving interpretations of the environment. In addition, same researchers presented that increases in relationship conflicts would increases thoughts of quitting or developing the intention of leave from the organization. Based on this model researchers, concluded that absence or poor positive relational experiences (support from the other employees) do not impact on employees' turnover decision and but high degree of relationship conflicts have impact on employees' turnover decisions. Therefore, current study adopted this model partially to develop the conceptual model of the association between conflicts and employees' intention to leave from the organization.
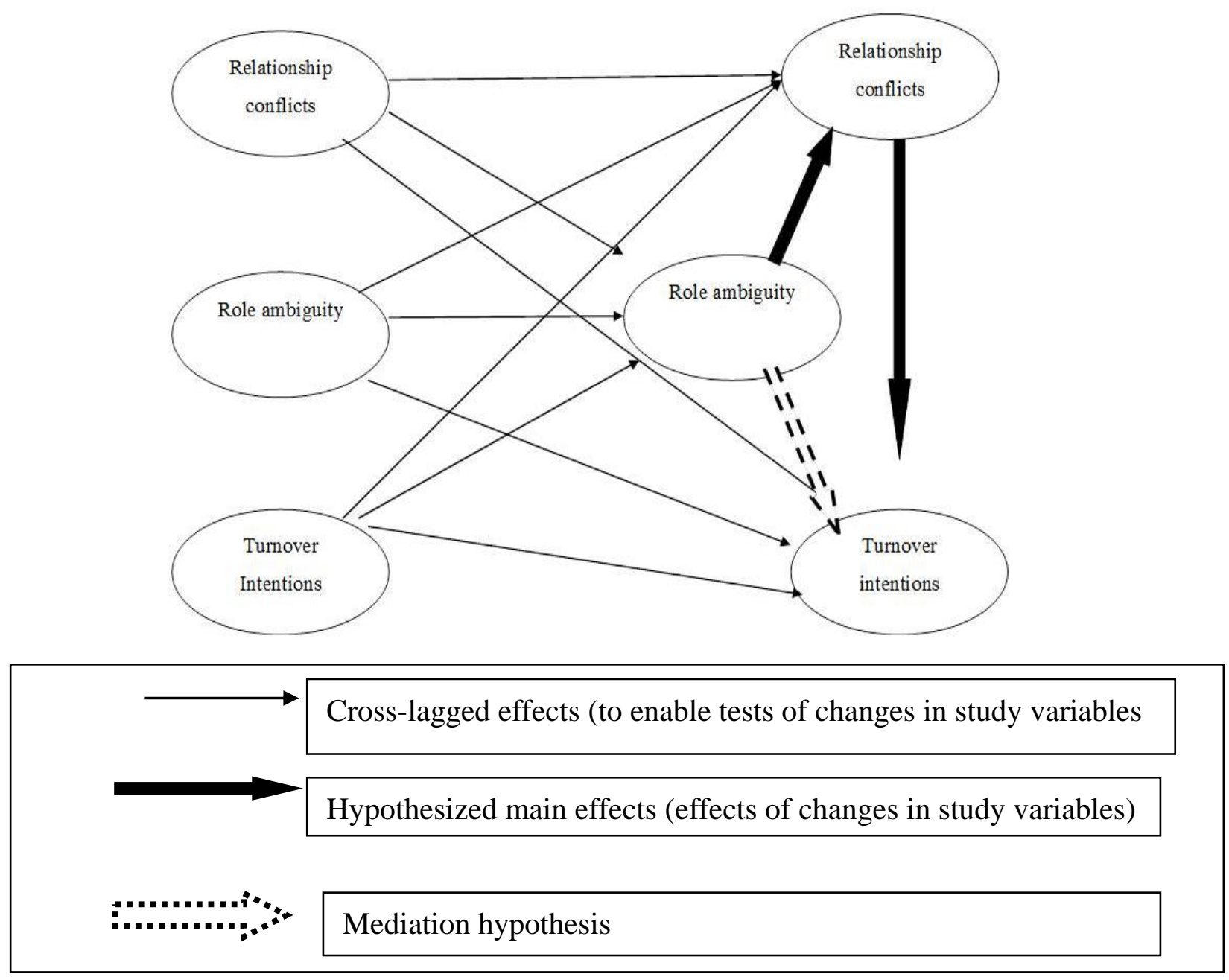

Figure 3.1. Theoretical Model Introduced for Relationship Conflict and Turnover Intentions (Hill et al., 2015)

Theoretical Model Introduced for Relationship Conflicts in Supervisor-Subordinate Dyads (Ismail et al., 2012)

Based on the research findings, researchers found that there is a connection between negative moods and positive moods to the impact the level of relationship conflicts experienced by subordinates (Ismail et al., 2012). Subordinates' collectivism values support to strengthen the positive moods or negative moods interaction on relationship conflicts. Same researchers implied that the association between conflicts and employees' intention to quit and trust in supervisors can be moderated by mentoring and supervisor-subordinate dyad tenure. Based on this theoretical model researcher selected relationship conflict as independent variable and employees' intention to leave from organization as dependent variable. This theoretical model can be explained by below figure. 


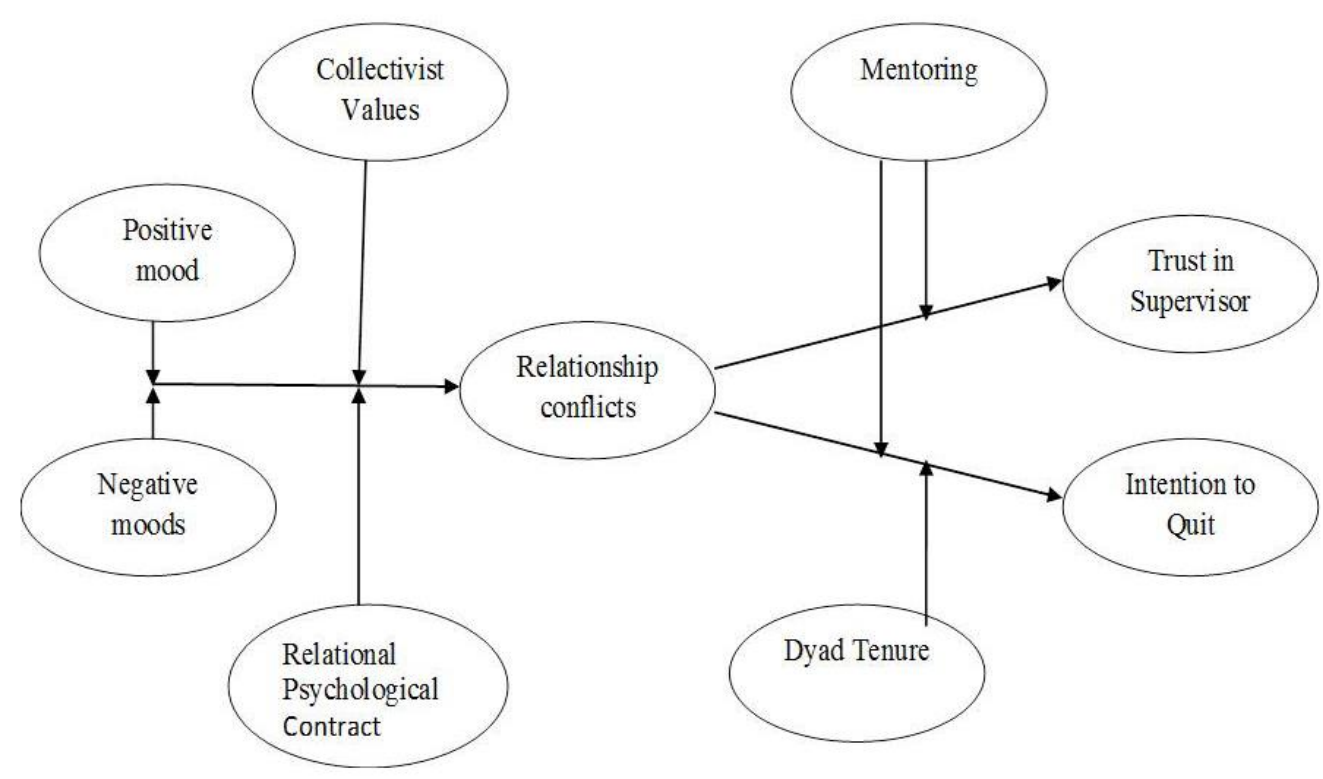

Figure 3.2. Theoretical Model Introduced for Relationship Conflicts and Turnover Intentions (Ismail et al., 2012)

Source: Ismail et al. (2012)

\section{Theoretical Model Introduced for Turnover and Intention to Quit (Alexander et al., 1998)}

This model implied that turnover process consists with three steps known as attitudinal, decisional and behavioral process (Alexander et al., 1998). According to this model, behavioral component helps to separate employees from the jobs in the organization. This behavior can be predicated by the decisional component of this model. According to this model attitudinal component influenced to employees' intention to leave (decisional component) and then turnover (behavioral component). As per this model, there are nine dimensions which affect employees' intention to leave from the organization; those are relationship with customers, relationship with co-workers, workload, professional growth and opportunities, pay and rewards, autonomy, work hazards, material resources and role clarity. Among these nine dimensions opportunities for professional growth, relationships with co-workers, autonomy and workload were the strongest predictors of intention to quit. Same researchers stated that healthy relationship with co-workers (minimum level of relationship conflicts) discourage the employees' intention to leave from the organization. Figure 3.3 illustrates the theoretical model introduced for turnover and intention to quit. 


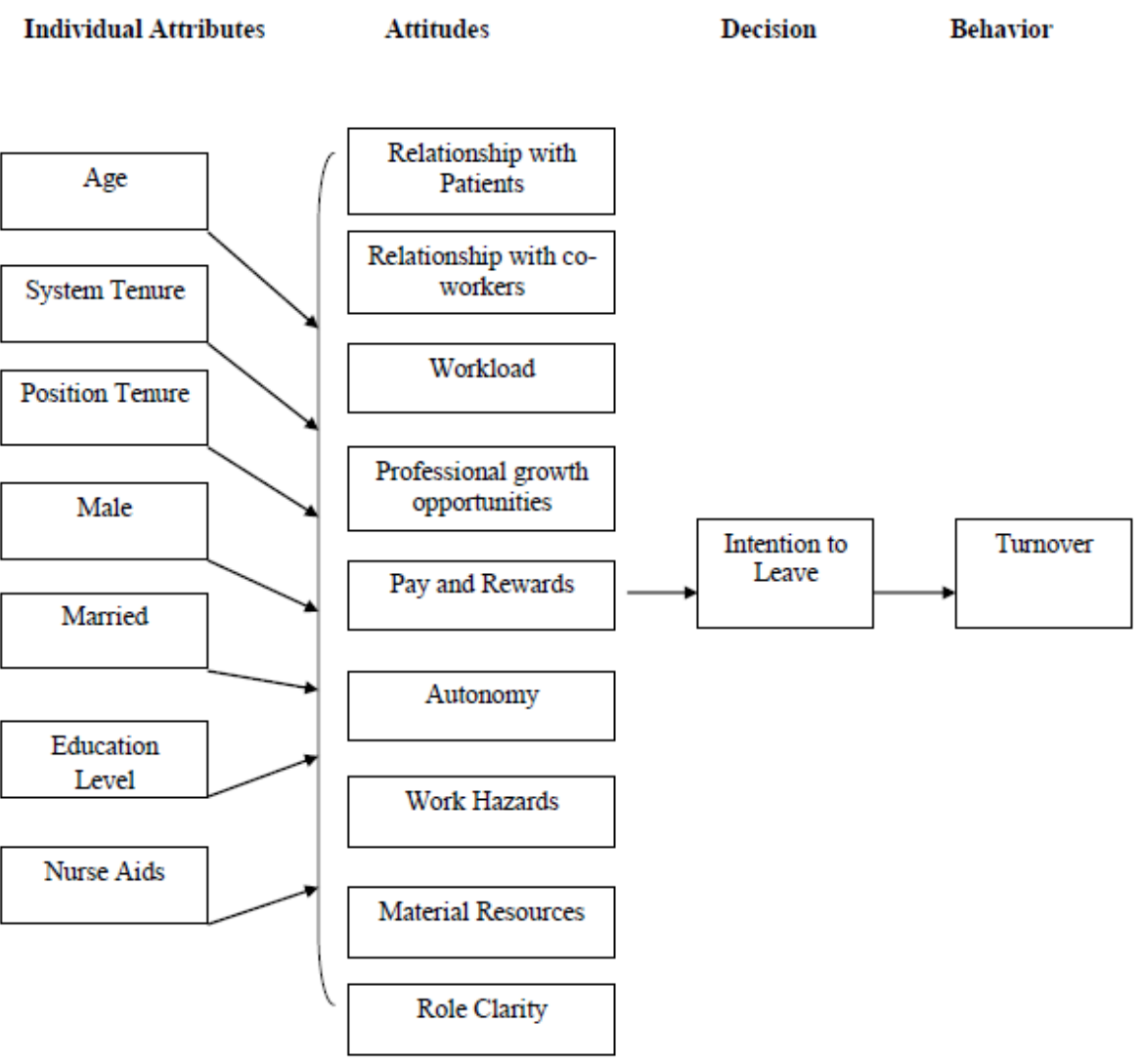

Figure 3.3. Theoretical Model Introduced for Relationship Conflicts and Turnover Intentions (Alexander et al., 1998)

Source: Alexander et al. (1998)

\section{Key Definitions of Concepts and Explanations: Relationship Conflicts}

Based on the theories in conflict literature, conflicts can be conceptualizing that as a process linking environmental antecedents to individual reactions (Wall and Callister, 1995). In the current study, researcher has taken satisfaction with the group and liking of group members as individual reactions under the relationship conflicts or affective conflicts based on Jehn (1995) study, in order to measure the relationship conflicts or affective conflicts.

\subsection{Satisfaction with the Group}

Based on the literature, there are much more evidence that individual affective reactions and their individual performance relationship conflict as a significant influence on outcomes of the group. Group members who felt tension and experienced in relationship conflict with person are dissatisfied in the relationship than those who have not experienced in relationship conflicts and felt tension (Surra and Longstreth, 1990). Members who are experiencing interpersonal tension are less satisfied with the group which they are working due to the interpersonal problems or relationship conflicts. Those interpersonal problems or relationship conflicts enhance negative reactions among the group members which lead to dissatisfaction among group members (Jehn,1995). Same author stated that negative individual reactions are created uncomfortable feelings among members which hinder the ability to enjoy each other in the work groups in the organization.

According to Baron (1990) stated that relationship conflicts create negative feelings or reactions among group members and they are not satisfied with their co-members in the group. Previous studies indicated that group members who have relationship conflicts experience dissatisfaction among with other group members. Shah and Jehn (1993) stated that relationship conflicts or affective conflicts influence to group performance, member satisfaction and the likelihood to work in the same group in future. This finding is consistent with Jehn (1995) studies. Same researcher stated that members who involved in relationship conflicts or emotional conflicts dislike to work with group members whom they have experienced the relationship conflicts. Some group 
members requested to redesign their tasks in-order to avoid the interaction with group members whom they have experienced relationship conflicts or emotional conflicts. According to Jehn (1995) personal issues and relationship conflicts detrimental to satisfaction and to the survival of the group. Same researcher stated that relationship conflicts caused to distress which lead to withdrawal from the group.

Relationship conflicts interfere with team performance and reduces satisfaction because it produces tension, antagonism and distracts team members performing the task (De Dreu and Weingart, 2003). Based on the empirical evidences, there is a strong support for the negative association between conflicts or emotional conflicts with employees' affective reactions such as satisfaction (De Dreu and Van Viannen, 2001; Jehn and Mannix, 2001). On the basis of above literature, satisfaction with group members selected as a dimension to measure the relationship conflicts.

\subsection{Liking to Colleagues}

Studies on conflict management found that group members who have relationship conflicts dislike working with members who have created the conflicts. More relationship conflicts may increase the thoughts of leaving of group members and gradually destroy employees' desire to associate with others at work (Hill et al., 2015). As mentioned earlier relationship conflicts create negative reactions.

\subsection{Employees' Intention to Leave from the Organization}

Employees' intention to leave refers to individual's own expected chance that they will quit the organization permanently in near future (Vandenberg and Nelson, 1999). Also, intent to leave can be defined as employees' determination for intention to leave the current job and looking forward to find another one (Purani and Sahadev, 2007).

\subsubsection{Job Hopping}

It refers to the behavior and attitude where employees transfer from one job to another job without any rationale or better alternatives (Kumar and Govindarajo, 2014). Researchers of the current study used Job hopping as one dimension to measure the employees' intention to leave from the organization.

\subsubsection{Perceived Alternative Employment Opportunities}

It can be defined as individual's perception of the availability of alternative job opportunities in the job market (Kumar and Govindarajo, 2014). ). Researchers of the current study used perceived alternative employment opportunities as one dimension to measure the employees' intention to leave from the organization.

\section{Proposed Conceptual Framework}

Conceptual framework is described and elaborated network of associations among the variables based on the theoretical models of the study. Two variables are undertaken to test the association between relationship conflicts and employees' intention to leave. As one of the objectives of the study to identify the association between s conflicts on employees' intention to leave from the organization, employees' intention to leave from the organization can be considered as the dependent variable.

According to literature review there are various types of conflicts, relationship conflicts are selected by researcher under independent variable.

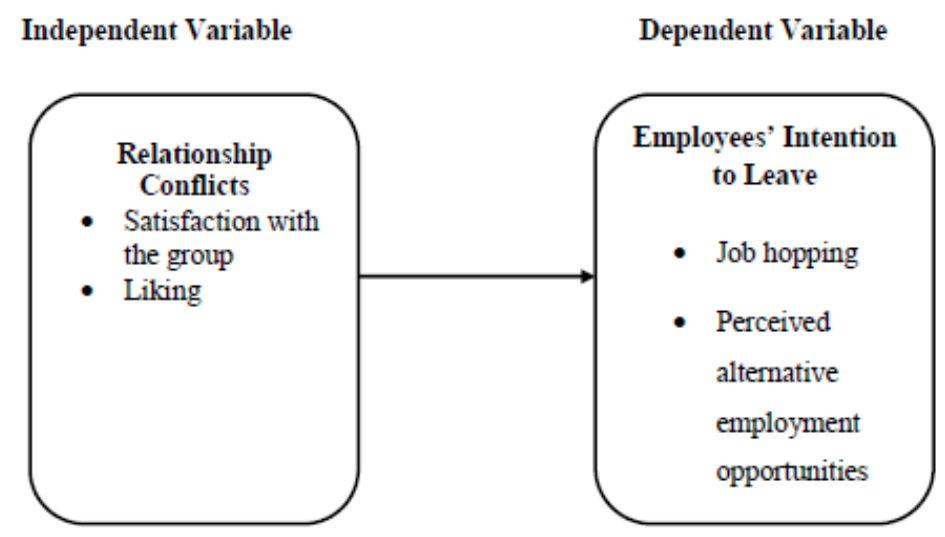

Figure 3.4. Conceptual Framework

Source: Researcher's original construction 


\section{Conclusion}

Researcher has developed a conceptual framework to test the association between relationship conflicts and employees' intention to leave with the support of previous research findings. Major importance of this research article is it provides logical base to develop hypothesis in-order to test the association between relationship conflicts and employees' intention to leave.

As suggestions to future researchers, they will be able to test the model in any kind of organization and prove that there is an association between relationship conflicts and employees' intention to leave. Further, future researchers can extend this model by adding moderating variables such emotional intelligence, organizational citizenship behavior etc.

\section{References}

Alexander, J., Lichtenstein, R., Oh, H., \& Ullman, E. (1998). A causal model of voluntary turnover among nursing personnel in long-term psychiatric settings. Research in Nursing \& Health, 21(5), 415-427. https://doi.org/10.1002/(SICI)1098-240X(199810)21:5<415::AID-NUR5>3.0.CO;2-Q

Amason, A. (1996). Distingushing the effects of functional and dysfunctional conflict on strategic decision making: resolving a paradox for top management groups. Academy of Management Journal, 39, 123-148.

Baron, R., Fortin, S., Frei, R., Hauver, L., \& Shack, M. (1990). Reducing Organizational Conflict: The Role of Socially - Induced Positive Affect. International Journal of Conflict Management, 1(2), 133-152. https://doi.org/10.1108/eb022677

De Dreu, C., \& Van Vianen, A. (2001). Managing relationship conflict and the effectiveness of organizational teams. Journal of Organizational Behavior, 22(3), 309-328. https://doi.org/10.1002/job.71

de Wit, F., Greer, L., \& Jehn, K. (2012). The paradox of intragroup conflict: A meta-analysis. Journal of Applied Psychology, 97(2), 360-390. https://doi.org/10.1037/a0024844

Hill, K., Chênevert, D., \& Poitras, J. (2015). Changes in relationship conflict as a mediator of the longitudinal relationship between changes in role ambiguity and turnover intentions. International Journal of Conflict Management, 26(1), 44-67. https://doi.org/10.1108/JJCMA-11-2013-0091

Ismail, K., Richard, O., \& Taylor, E. (2012). Relationship conflict in supervisor-subordinate dyads:a subordinate perspective. International Journal of Conflict Management, 23(2), 192-218. https://doi.org/10.1108/10444061211218302

Jehn, K. (1994). Enhancing Effectiveness: An Investigation of Advantages and Disadvantages of Value-Based Intragroup Conflict. International Journal of Conflict Management, 5(3), 223-238. https://doi.org/10.1108/eb022744

Jehn, K. (1995). A Multimethod Examination of the Benefits and Detriments of Intragroup Conflict. Administrative Science Quarterly, 40(2), 256. https://doi.org/10.2307/2393638

Jehn, K., \& Chatman, J. (2000). The Influence of Proportional and Perceptual Conflict Composition on Team Performance. International Journal of Conflict Management, 11(1), 56-73. https://doi.org/10.1108/eb022835

Kumar, M. D., \& S Govindarajo, N. (2014). Instrument Development: "Intention to Leave Instrument. Middle-East Journal of Scientific Research, 21(3).

Kumar, N. (2009). Organizational Behaviour : A New Look: Concept, Theory \& Cases. Himalaya Pub. House.

Medina, J., Munduate, L., Miguel, A., Martinez, I., Guerra, \& Jose, M. (2005). Types of intragroup conflict and affective reactions. Journal of Managerial Psychology, 20, 219-230. https://doi.org/10.1108/02683940510589019

Pelled, L. (1996). Demographic diversity, conflict, and work group outcomes: An intervening processs theory. Organizational Science, 7, 615-631. https://doi.org/10.1287/orsc.7.6.615

Purani, K., \& Sahadev, S. (2007). The moderating role of industrial experience in the job satisfaction, intention to leave relationship: an empirical study among salesmen in India. Journal of Business \& Industrial Marketing, 23(7), 475-485. https://doi.org/10.1108/08858620810901239

Rahim, A. M. (2001). Managing conflict in organizations. 3rd edn. United States: Quorum Books, U. S. https://doi.org/10.2139/ssrn.2247886

Riaz, M., \& Junaid, F. (2013). Workplace Conflict: Constructive or Destructive. SSRN Electronic Journal. 
Shah, P., \& Jehn, K. (1993). Do friends perform better than acquaintances? The interaction of friendship, conflict, and task. Group Decision and Negotiation, 2(2), 149-165. https://doi.org/10.1007/BF01884769

Surra, C., \& Longstreth, M. (1990). Similarity of outcomes, interdependence, and conflict in dating relationships. Journal of Personality and Social Psychology, 59(3), 501-516. https://doi.org/10.1037/0022-3514.59.3.501

Vandenberg, R., \& Nelson, J. (1999). Disaggregating the Motives Underlying Tiarnover Intentions: When Do Intentions Predict Thrnover Behavior? Human Relations, 52(10), 1313-1336. https://doi.org/10.1177/001872679905201005

\section{Copyrights}

Copyright for this article is retained by the author(s), with first publication rights granted to the journal.

This is an open-access article distributed under the terms and conditions of the Creative Commons Attribution license (http://creativecommons.org/licenses/by/4.0/). 